\title{
SUBJETIVIDADES
}

Edição Especial:

A Psicanálise e as Formas do Político

\section{CINCO NOTAS SOBRE O FEMINICÍDIO A PARTIR DA PSICANÁLISE}

Five Notes on Feminicide from Psychoanalysis

Cinco Notas sobre el Feminicidio a partir del Psicoanálisis

\section{Cinq Notes sur le Féminicide sur le point de vue de la Psychanalyse}

DOI: $10.5020 / 23590777 . r s . v 18 i E s p .6174$

Renata Damiano Riguini, (OrcID)

Psicanalista. Pós-doutoranda no Programa de Pos Graduação em Psicologia da PUC-Minas.

\section{Cristina Moreira Marcos (OrcID)}

Psicanalista, Docente do Programa de Pós-Graduação em Psicologia de PUC-Minas, Doutora em Psicanálise pela Universidade de Paris 7.

\section{Resumo}

Neste artigo, trabalhamos a questão do feminicídio dentro da perspectiva da psicanálise. Entendendo que, nesta abordagem, este tipo de violência não se pauta na diferença sexual, já que é entendido como um crime endereçado ao feminino, conceito lacaniano que não se esgota na dicotomia homem/mulher. Em cinco notas, abordamos o problema do horror ao gozo feminino na teoria psicanalítica e nas invenções dos sujeitos - homens e mulheres - para lidar com o héteros, soluções da catástrofe à arte.

Palavras-chave: feminicídio; feminino; gozo do Outro; violência.

\section{Abstract}

In this article, we address the issue of feminicide within the perspective of psychoanalysis. Understanding that in this approach, this type of violence is not based on sexual difference, since it is understood as a crime addressed to the feminine, a Lacanian concept that is not exhausted in the male / female dichotomy. In five notes, we address the problem of female horror in psychoanalytic theory and the inventions of subjects - men and women - to deal with heterosexuals, solutions from catastrophe to art.

Keywords: feminicide; female; enjoyment of the Other; violence.

\section{Resumen}

En este artículo trabajamos la cuestión del feminicidio dentro de la perspectiva del psicoanálisis. Entendiendo que, en este enfoque, este tipo de violencia no se basa en la diferencia sexual, ya que es comprendido como un crimen dirigido al femenino, concepto lacaniano que no se agota en la dicotomía hombre/mujer. En cinco notas, tratamos el problema del horror al gozo femenino en la teoría psicoanalítica y en las invenciones de los sujetos - hombres y mujeres - para lidiar con el hetero, soluciones de la catástrofe al arte.

Palabras claves: feminicidio; femenino; gozo del Otro; violencia.

$1 \quad \mathrm{O}$ artigo foi escrito a partir de uma pesquisa de pós-doutorado financiada pela Capes e integrou as discussões ocorridas durante a pesquisa "O que quer uma mãe hoje: um estudo da maternidade no século XXI a partir da psicanálise”, financiada pela FAPEMIG. 


\section{Résumé}

Dans cet article, nous travaillons la question du féminicide dans la perspective de la psychanalyse. Dans cette approche, ce type de violence n'est pas marqué dans la différence sexuelle, puisqu'il est compris comme afrdressé au féminin, conception lacanienne, qui ne finit pas dans la dichotomie hommelfemme. En cinq notes, on aborde le problème de l'horreur de la jouissance féminine chez la théorie psychanalytique et chez les inventions des sujets - des hommes et des femmes - pour traiter avec l'Héteros, des solutions de la catastrophe à l'art.

Mots-clés: féminicide; féminin, jouissance de l'autre; violence.

O feminicídio, expressão última das diversas formas de violência contra a mulher, é um tema recorrente nos nossos dias. Desde os jornais mais polêmicos, que se esbaldam com as notícias de crimes contra a mulher, ao interior dos consultórios de psicanálise, o abuso contra a mulher e o feminicídio assumem um crescente lugar de destaque. Em oito de março de 2015, a então presidenta Dilma Rousseff e a câmara aprovaram a Lei n. 13.104/15, que inclui no Código Penal esta modalidade de homicídio qualificado, o feminicídio. O feminicídio é o crime praticado contra a mulher em função da condição do sexo feminino. Essa condição se estabelece, segundo a lei, em dois casos: violência doméstica e familiar, e menosprezo ou discriminação à condição de mulher. Segundo relatório da Comissão Parlamentar Mista de Inquérito sobre a violência contra a mulher, de 2013, o feminicídio é:

a instância última de controle da mulher pelo homem: o controle da vida e da morte. Ele se expressa como afirmação irrestrita de posse, igualando a mulher a um objeto, quando cometido por parceiro ou ex-parceiro; como subjugação da intimidade e da sexualidade da mulher, por meio da violência sexual associada ao assassinato; como destruição da identidade da mulher, pela mutilação ou desfiguração de seu corpo; como aviltamento da dignidade da mulher, submetendo-a a tortura ou a tratamento cruel ou degradante (Relatório final, CPMI-VCM, 2013, apud Dossiê Feminicídio).

Segundo o Dossiê Feminicídio \#InvisibilidadeMata, do Instituto Patrícia Galvão (2016), o feminicídio é um crime mais comum em sociedades marcadas pela discriminação da mulher. O Brasil está entre os países como maior índice desse crime, ocupando o quinto lugar em um ranking com oitenta e três países. Ao longo dos anos, o número de vítimas vem crescendo. De 2003 a 2013, espaço de uma década, esse número cresceu 21\%, atingindo a marca, em 2013, de 13 homicídios femininos por dia no país. Vale ainda apontar que, no Brasil, 50,3\% dos assassinatos de mulheres foram cometidos por familiares, sendo 33,2\% praticados por parceiros ou ex-parceiros da vítima (Instituto Patrícia Galvão, 2016).

A psicanálise, convidada a se posicionar frente às questões de sua época, trata a questão dos crimes contra mulher - assassinatos e abusos - de uma maneira diferente dos dispositivos jurídicos. Uma diferença importante se coloca de saída. Para a psicanálise, tais crimes não se direcionam à mulher enquanto gênero, ou seja, não visam atacar a mulher em seu papel social. A nosso ver, é uma violência direcionada ao feminino - conceito mais amplo, forjado por Jacques Lacan, em que a diferença não incide sobre a anatomia, mas em uma forma distinta de gozo, como será esclarecido ao longo deste artigo. Nesse sentido, para Alvarenga (2015), os homossexuais podem ser o alvo da mesma violência contra a mulher, já que se configura como um ataque ao héteros.

Destacamos também que a lei que pune a violência familiar, a Lei Maria da Penha², vigente no Brasil desde agosto de 2006, associada às campanhas de proteção às mulheres amparadas por esta lei, não traz o resultado esperado, já que, como vimos, o número destas que sofrem violência de seus parceiros ainda cresce. Sabemos o quão comum é o fato de que as vítimas não recorram à lei para se protegerem, e as que o fazem, muitas vezes, logo retiram suas queixas. Como observaram Galo (Galo et al., 2010), alguns elementos da subjetividade feminina impedem que aconteçam transformações íntimas em consonância com as transformações sociais conquistadas por movimentos de mulheres. As mudanças sociais e jurídicas são essenciais para começarmos a tratar o problema, mas já constatamos que tais benefícios não são aceitos "de maneira automática e sem conflitos, como se não existisse a culpa, o medo e a desautorização" (p. 18) por parte das mulheres/vítimas. Assim, as leis são uma via absolutamente necessária, mas é evidente que se mostram insuficientes. A psicanálise não deixa essa dimensão esquecida ao tratar do problema.

Vale ainda destacar que, em psicanálise, a perspectiva que trata do problema a partir do par vítima-algoz é estéril, já que não lança nenhuma luz às questões que nos colocamos. Por essa via de entendimento da questão, o tratamento do assunto, muitas vezes, passa por medidas educativas focadas na erradicação das condutas. Esses mecanismos provam um profundo

2 Lei Maria da Penha é o nome popular da lei número 11.340 de 7 de agosto de 2006. A lei é um dispositivo legal que tem como objetivo aumentar o rigor das punições sobre crimes domésticos. Usualmente ela é aplicada em homens que agridem fisca ou psicologicamente uma mulher, que na maior parte das vezes é sua própria esposa. 
desconhecimento da pulsão de morte que permeia as relações. Sabemos, a partir da psicanálise, que a tensão agressiva, a violência contra o semelhante, o mal, são elementos nucleares da constituição de cada sujeito (De Francisco, 2014). $\mathrm{O}$ desconhecimento dessa condição humana ao abordarmos a questão da violência contra a mulher através de medidas corretivas continua nos mostrando que insiste a reincidência, tanto por parte do agressor quanto da vítima. A autora adverte ainda que a promoção de uma homogeneidade entre os sexos tende a apagar a singularidade de cada um. Para ela, "o homogêneo, o idêntico, ainda que em princípio possa parecer que conduzirá a algo harmônico, vai gerar um aumento da tensão agressiva e da violência entre os vínculos" (p. 85).

Sabemos também que a violência contra as mulheres é atemporal. A imagem do homem das cavernas puxando uma mulher pelos cabelos é facilmente resgatada por todos nós (Alvarenga, 2015). Podemos, inclusive, assegurar que a violência, em geral, é uma manifestação humana essencial. Afirmaremos ainda que o discurso de cada época convoca a determinados modos de apresentação dessas manifestações. Como nos aponta Marotta (2014, p.26), "como sintoma do sujeito, e mesmo como sintoma social, sempre há algo velho e algo novo na violência". Nesse sentido, a pulsão de morte freudiana é o velho e imutável elemento da violência. O que muda com a época são as construções que fornecem os motivos da violência, tais como: disputas territoriais, luta por bens, poder, demarcações ideológicas, entre outras.

A violência de nossa época vem marcada, especialmente, por uma civilização que já não se ordena tanto pelos ideais, mas sim pelo discurso capitalista e da tecnologia que daí advém. Essa configuração promove, a partir das leis de mercado, uma proliferação de objetos produzidos para serem consumidos e logo descartados. Tais condições, segundo Marotta (2014), deixam o sujeito desprovido e despojado de seus planos e previsões, ficando à mercê das falhas simbólicas e da vacilação dos semblantes.

A queda dos ideais é mais uma consequência de uma época que se configura a partir da inexistência do Outro, consequentemente, do declínio do pai e da prevalência dos objetos de gozo. Tal configuração traz consequências que podemos observar nas relações entre os sexos. No que toca nosso tema, é possível perceber que, embora as mulheres tenham conseguido certa igualdade em termos sociais, laborais e jurídicos, há um aumento da violência como modo de fazer vínculo com o Outro sexo por parte dos homens. E ainda, embora a mulher avance em termos de conquistas em vários aspectos -, nunca ela assumiu um lugar tão vitimizado. Para Sawicke (2014), o declínio do Nome-do-Pai tem como efeito um aumento das tensões agressivas entre homens e mulheres. A discussão da violência de gênero, pela psicanálise, não deixa de considerar essa perspectiva.

Esclarecidos esses primeiros apontamentos, buscaremos recortar nossa discussão. Ao pesquisarmos o tema do feminicídio pelo viés psicanalítico, percebemos que existiam várias formas de nos aproximarmos da questão. A partir da pesquisa realizada no pósdoutorado, foi se demarcando um campo que atravessa o problema da violência contra a mulher, mas que ainda se manifesta na clínica de diversas formas, entre homens e mulheres: a diferença introduzida no mundo pelo corpo da mulher e pelo gozo feminino.

\section{Primeira Nota: A Mulher para Além dos Direitos Humanos}

A violência contra a mulher vem ganhando os espaços de discussão em nossa época. Essa discussão tem incidências no plano social e jurídico, onde buscam a remissão dessas agressões. No entanto, essa forma de violência tem um caráter universal, ou seja, existiu em todas as épocas em quaisquer lugares. Para Bassols (2012), onde há cultura, há violência contra a mulher. Hoje, os direitos humanos buscam igualar as condições entre os sexos e condenam a violência contra a mulher. Certamente, os direitos humanos devem ser universais, servindo para todo cidadão, independente de sexo, cor ou qualquer outra diferença.

Mas a igualdade dos direitos humanos, como afirmou De Francisco (2014), não pode apagar as diferenças subjetivas entre os sexos. Para a autora, a violência de gênero está intimamente ligada à diferença dos sexos, e acrescenta que ela também é transversal às estruturas. Logo, refere-se a como cada sujeito (neurótico, psicótico ou perverso), assume sua posição sexuada e como lida com a alteridade que representa a mulher no mundo Por sua vez, Dafunchio (2008, p. 133) acrescenta que "quando falta o limite da castração o feminino toma a significação de algo mal, é a sede maligna do gozo". Nos casos de violência doméstica, os maus tratos à parceira, que encarnam o feminino para aquele sujeito que maltrata, mostram uma verdadeira impotência do homem para abordar e, inclusive, para amar uma mulher. Assim, "frente a incapacidade de amar esta radical alteridade, o homem está tentado a violá-lo, degradá-lo, humilhá-lo" (De Francisco, 2014, p.86). Vale enfatizar ainda que a alteridade da mulher não é uma questão só para o homem, já que a mulher também se encontra com esse corpo que precisa sustentar, e o gozo correspondente que experimenta.

A saída para muitas mulheres, frente à alteridade de seu corpo, frente ao feminino que encarnam, passa, muitas vezes, pela maternidade. A figura da mãe, nesses casos, vem para tamponar o horror ao feminino. Galo, Jaramillo, Marroquin e Ramirez (2010) nos recorda que nas mulheres-mães o imperativo que modela seus atos não é o de reivindicar autonomia e direitos iguais, mas uma aparente negação à própria satisfação. Assim, a mulher-mãe adota os semblantes do sacrifício e da abnegação, que escondem um querer que só pode ser decifrado caso a caso, impossível de interpretar a partir da igualdade 
de gêneros. Frente à liberdade conquistada pelas mulheres em relação às suas decisões e autonomia, vemos se erguer um muro de imobilidade dado pela conservação desta antiga posição materna, superegóica, que estabelece um "você não tem direito", ou "você não merece" (Galo et al., 2010). Estes significantes não vêm do Outro, de um algoz, mas de si mesmas e, muitas vezes, impedem que essas mulheres busquem sair da situação de ser agredida.

Ocupar o lugar de objeto degradado traz alguns benefícios inconscientes. Para Ubieto (2008), p. 3), "ser a amante eterna, sempre disposta, deste outro que maltrata, para algumas mulheres supõe dar-se um ser como mulher, e sobretudo como mãe”. Não raro é possível escutar dessas mulheres um lamento quando seus parceiros são detidos. Esse lamento sobre a sorte do homem que maltrata passa, muitas vezes, pela interrogação: "o que será dele agora que não tem a mim para cuidar?”. A tendência para ocupar um lugar sacrificial é muito difícil de ser ultrapassada.

Frente a tais constatações, fica claro que não é possível lidar com o problema a partir da solução da igualdade. Não basta oferecer a essas mulheres ajuda para romper a parceria, já que, conforme coloca Ubieto (2008), a ruptura "lhes abre um horizonte de vazio e de perda que provoca uma angústia paralisante" (p.4). Uma efetiva mudança no posicionamento das mulheres só pode acontecer se houver uma mudança subjetiva. Sem ela, os logros sociais, legais, a independência financeira, o sucesso laboral, não podem alcançar a mudança ambicionada.

\section{Segunda Nota: A mulher como Figura do Abismo}

Antes de entrarmos na discussão propriamente psicanalítica, retomaremos algumas formas de apreensão do enigma que se impõe à mulher em nossa cultura. Essas figuras, por muitas vezes, por estarem fora do sentido, estarão ligadas às figuras do mal ou da fúria da natureza. Assim, frente a um gozo que, como veremos, não pode regular-se falicamente, esse mesmo gozo começa a tomar as formas do feminino como diabo, prostituta, ou como a mulher que carrega o mal para seu lar e seu marido - como fez Eva com Adão ou Jezabel com Acabe.

Eva, em Gênesis 3: 6-7, come do fruto proibido por Deus na árvore do Bem e do Mal, e o entrega à Adão. Adão e Eva teriam sido feitos à imagem e semelhança de Deus, mas, depois desse fato, tornam-se humanos e condenados ao pecado. A figura de Eva, segundo Delumeau (1990), leva a uma diabolização da mulher na Idade Média. Adão só come a maça do pecado por temor de ficar sem Eva no paraíso, portanto, por amor, ou por fidelidade, paixões diferentes da curiosidade e rebeldia de Eva. O autor nos traz um recorte da teologia medieval ilustrativo dessa condição: "Tu deverias usar sempre luto, estar coberta de andrajos e mergulhada na penitência, a fim de compensar a culpa de ter trazido a perdição ao gênero humano (...). Mulher, tu és a porta do diabo. Foste tu que tocaste a árvore de Satã e que, em primeiro lugar, violaste a lei divina” (p. 316).

Jezabel, a mulher estrangeira do I Livro dos Reis no Antigo Testamento, sedutora e sem escrúpulos, corrompe o marido. Ela era uma princesa fenícia, politeísta, que se casou com Acabe, rei de Israel. Ela, uma rainha cheia de adornos, não só continuou a adorar deuses fenícios, como influenciou o marido a construir vários templos e também a adorar seus deuses. Uma revolta se instalou em Israel e o profeta Elias protagoniza a perseguição ao reinado e arranja a violenta morte de Jezabel, legitimada pela palavra de Javé. Com o assassinato dessa mulher, e seus deuses e deusas, está garantida a ordem e o monoteísmo masculino - podemos acrescentar fálico - em Israel (Oliveira, 2008).

Para Ons (2012), na Bíblia e na tradição patriarcal, as mulheres são governadas por seu sexo e por esse pecado o mundo se torna profano. Por consequência, teremos a morte, o sofrimento e o trabalho. Aos homens, cabe a tarefa de vigiar e punir as mulheres e sua sexualidade desgovernarda e perigosa para humanidade. Já que esse corpo não pode se manter casto, que seja restringido à maternidade, forma de "domesticar e amarrar o gozo feminino, vivido como sem limites e errante" (p. 23).

$\mathrm{O}$ inquietante do gozo feminino está no excesso, na ultrapassagem dos limites, o que serve como justificativa para aplicação das normas de controle. Na Idade Média, a mulher era, portanto, confinada ao quarto, ao claustro, a espaços interiores, a fim de manter o excesso contido. Mas, nos dias de hoje, muito nos afastamos da Idade Média. Se antes a repressão da sexualidade era a norma, podemos dizer que hoje se propaga sua liberação. Mesmo assim, a sexualidade continua vigiada e sujeita a enquadramentos que, se já não são repressivos, ainda nos apontam uma dificuldade para abordar a sexualidade feminina e seus desdobramentos.

Ora, se acrescentarmos termos lacanianos a esse desenvolvimento, podemos ligar a figura da mulher ao real ${ }^{3}$ na medida em que seu gozo não tem limites - não é todo limitado pela castração -, presentificando o abismo e a vertigem que imperam fora do simbólico, fora da norma fálica. Veremos, portanto, o tratamento que a psicanálise dá ao gozo feminino.

3 O real, na perspectiva lacaniana dos anos 70, em resumidas palavras, é o que não pode ser dito. Esá fora do discurso, e não cessa de não se escrever. O real é o impossível de ser captado por qualquer instrumento simbólico, ele justamente escapa a simbolização. Para esta discussão sugerimos o artigo de Pitteri (2010) “Jacques Lacan: O simbólico, o imaginário e o Real”. 


\section{Terceira Nota: A Mulher Tabu}

Desde Freud, a diferença entre os sexos é objeto de observação e discussão na psicanálise. Já em 1905, Freud destaca três teorias sexuais infantis ao buscar estabelecer os andaimes da sexualidade na criança. Para nosso trabalho, é importante frisar que duas dessas teorias, a teoria fálica (todos possuem pênis) e a teoria cloacal (os bebês nascem pelo ânus), têm em comum o desconhecimento, por parte da criança, da diferença sexual. ${ }^{4}$

Mais tarde, em 1923, ainda debruçado sobre os efeitos da diferença entre os sexos para meninos e meninas, Freud continua a enfatizar a primazia do falo e suas consequências, ter ou não ter o falo, como organizadora da sexualidade na infância. Tal primazia "consiste no fato de, para ambos os sexos, entrar em consideração apenas um órgão genital, ou seja, o masculino" (Freud, 1923/1996b, p. 158). Assim, continua Freud, o que está presente não é uma primazia dos órgãos genitais, mas uma primazia do falo. Alvarez (2016b) nos esclarece que, para Freud, o falo, que não se confunde com o órgão genital masculino, é uma imagem pregnante da forma fálica, fixada como símbolo da sociedade patriarcal que está presente em todas as culturas, desde a Antiguidade. A percepção da ausência do pênis pela criança será vista como castração, e assumirá seus efeitos. Freud mostra que o complexo de Édipo e o complexo de castração são articulados pelo falo.

"A diferença entre o desenvolvimento sexual dos indivíduos dos sexos masculino e feminino é uma consequência inteligível da distinção anatômica entre seus órgãos genitais e da situação psíquica aí envolvida; corresponde à diferença entre uma castração que foi executada e outra que simplesmente foi ameaçada" (Freud, 1923/1996b, p.285).

Em poucas palavras, podemos dizer que o complexo de castração destruirá, para os meninos, o complexo de Édipo. Pela ameaça de castração, os meninos recuam em sua rivalidade com o pai e no amor sensual à mãe. Para as meninas, ao contrário, o Édipo só é possível a partir do complexo de castração. Elas se percebem castradas, como a mãe, e se dirigem ao pai para ter acesso ao falo. Assim, para se posicionar como homem ou mulher, o sujeito se referencia no falo e na castração.

Em outro artigo de 1923, Freud, tratando da organização genital infantil, afirma novamente a primazia do falo para a criança e aponta para a dificuldade de enlaçar o feminino em uma trama simbólica. Assim, as crianças desconhecem o sexo feminino. Ele comenta que os meninos percebem a distinção entre meninos e meninas, mas que essa não está vinculada aos órgãos genitais. Vale lembrar que Freud conduz este texto a partir da observação dos meninos. Ele nos diz que "podemos descrever esse estado de coisas apenas no ponto em que afeta a criança do sexo masculino; os processos correspondentes na menina não conhecemos" (Freud, 1923/1996c, p.158). Para o menino, "é natural presumir que todos os outros seres vivos, humanos e animais, possuem um órgão genital como seu próprio" (Freud, 1923/1996c, p. 158). Mais tarde, descobre que nem todos têm pênis, normalmente pela visão de uma menina, ou mesmo uma mulher, nua.

Interessa-nos lembrar das reações dos meninos a esse fato. Segundo Freud (1923/1996c), primeiramente, eles rejeitarão a visão que tiveram, acreditando que, ainda assim, viram um pênis, que ele ainda é pequeno, mas que logo crescerá. Depois, lentamente, chegam à conclusão dolorosa de que o pênis esteve lá, mas foi retirado. Assim, a falta de pênis é entendida como castração. Tal conclusão tem seus efeitos. Para Freud, um alto grau de "depreciação das mulheres, o horror a elas e a disposição ao homossexualismo derivam da convicção final de que as mulheres não possuem pênis" (Freud, 1923/1996c, p. 160). Ressaltamos aqui, mais uma vez, a dimensão de desconhecimento do órgão sexual feminino. Mesmo sabendo que elas não possuem um pênis, as crianças não chegam a imaginar ou supor um órgão feminino, mas a acreditam castradas.

Alguns anos antes, em O Tabu da virgindade (Freud, 1917/1996a), investigando o tabu relacionado à perda da virgindade de uma mulher através do estudo dos tabus relacionados à sexualidade em povos primitivos, Freud chega a dizer que:

"Não é, apenas, o primeiro coito com uma mulher que constitui tabu e sim a relação sexual de um modo geral; quase se pode dizer que a mulher inteira é um tabu. ${ }^{5}$ A mulher não é tabu somente em situações especiais decorrentes de sua vida sexual, as relações sexuais com as mulheres estão sujeitas a restrições tão solenes e numerosas que temos muitas razões para duvidar da suposta liberdade sexual dos selvagens". (p. 215).

Para Freud (1917/1996a), um receio generalizado das mulheres se expressa em todas as regras de evitação que puderam ser observadas no homem primitivo - por exemplo, quando o homem buscava um empreendimento especial, era obrigado a se afastar da mulher; ou a tendência na vida diária desses povos a manterem separados os sexos. Freud coloca que talvez esse receio se baseie no fato de que a mulher é diferente do homem, "eternamente incompreensível e misteriosa, estranha e, portanto, aparentemente hostil" (p. 206). Assim, o homem teme ser enfraquecido pela mulher, "contaminado por sua feminilidade" (p. 206).

4 Vale dizer que este é um percurso longo e árduo na obra freudiana que aqui, limitados pela condição de artigo, só resgatamos os pontos mais importantes para nosso objetivo.

$5 \quad$ Grifo nosso. 
As práticas de tabus ligados à mulher, continua Freud (1917/1996a), supõem a existência de uma força que se opõe ao amor pela rejeição das mulheres, já que são percebidas como estranhas e hostis. Dessa maneira, a mulher é Outra para o homem e, como veremos, é Outra para si mesma. E podemos acrescentar que "esta alteridade da mulher é o princípio da degradação" (Gana, 2013, p.79). Freud ainda diz ser tentador explicar tamanho estranhamento e rejeição pela hostilidade do narcisismo das pequenas diferenças: o ódio se enlaça ao detalhe, podemos acrescentar que o que se odeia é o gozo do Outro. Entender a mulher como tabu, esclarece Gana (2013, p. 79), é vislumbrar uma dificuldade "interposta no homem para aceder ao gozo sexual, cujo reverso se manifesta nas mulheres como uma dificuldade para suportar o homem", ponto que ficará mais claro quando abordarmos a alteridade da mulher na próxima nota. Para completar, Freud argumenta que: "A psicanálise acredita que descobriu grande parte do que fundamenta a rejeição narcísica das mulheres pelos homens, a qual está entremeada com o desprezo por elas, ao chamar a atenção para o complexo de castração e sua influência sobre a opinião em que são tidas as mulheres" (Freud, 1917/1996a, p. 207).

A diferença sexual não será ignorada por Jacques Lacan quando retoma a obra freudiana. No entanto, suas elaborações o conduziram, nos anos 1970, às estruturas da sexuação que foram feitas, segundo Miller (2008, p.26), para articular o gozo próprio de cada sexo, ao "indicar a forma diferente que o gozo recebe ao ser alojado em uma ou outra dessas estruturas". Assim, a tábua da sexuação foi o artifício lacaniano para escrever a relação de cada sexo com seu gozo. Veremos como essa nova apreensão da mulher e do conceito de gozo feminino podem lançar luz sobre nossa questão.

\section{Quarta Nota: A Alteridade da Mulher como Princípio da Degradação - as formulações lacanianas}

Lacan, desde o começo de seu ensino, seguiu a via aberta por Freud para dar conta da repartição entre os sexos. Isto quer dizer que o complexo de Édipo e o complexo de castração são seus orientadores nesse campo. No primeiro tempo de seu ensino, ${ }^{6} \mathrm{o}$ falo será retomado como significante fálico, o qual normatiza as identificações viris e femininas partindo do complexo de Édipo. Em 'A significação do falo' (1958/1998), Lacan nos mostra que os fatos clínicos atestam que a relação do sujeito com o falo se estabelece desconsiderando a diferença anatômica entre os sexos. $\mathrm{O}$ falo é o significante privilegiado na relação do sujeito com a linguagem, já que é "o significante destinado a designar, em seu conjunto, os efeitos do significado" (Lacan, 1958/1998b, p. 697).

Nesta via edípica, Lacan (1960/1998a), em 'Diretrizes para um congresso sobre a sexualidade feminina', declara a impotência da psicanálise, e mesmo das ciências biológicas, para desvelar algo sobre o gozo feminino. Lacan fala da "obscuridade quanto ao órgão vaginal" (p. 736) e da natureza inviolada do orgasmo vaginal, que deixam a questão do gozo feminino intocada. Serão necessários alguns anos para que ele, através de uma nova lógica, possa lançar luz sobre essa questão.

No que conhecemos como segundo ensino de Lacan, a diferença sexual será tratada a partir da sexuação, ou seja, a partir da maneira como cada sujeito, homens e mulheres, relacionam-s com seu próprio sexo, com as questões da castração e da diferença entre os sexos (Chemama, 1995). Nestas elaborações dos anos 1970, Lacan trata então das estruturas da sexuação que foram feitas para articular o gozo próprio de cada sexo. Se o conceito de gozo era, antes dessas elaborações, tratado no singular, ele ganha agora uma referência no plural, já que cada falasser experimenta o gozo de forma diferente, a partir de sua posição sexuada. A proposta de Lacan é uma repartição dos sexos que não se sustenta na anatomia, ela é concebida a partir de sua relação com o gozo. Falaremos, aqui, em lado homem e lado mulher para facilitar nosso entendimento da questão, já que, como esclarece Teixeira (2014), ainda assim a diferença anatômica é dada por um órgão que representa o falo. Devemos frisar, no entanto, que nem todo homem estará regido pelas coordenadas colocadas do lado esquerdo do quadro, e nem toda mulher estará estabelecida no lado direito.

Do lado masculino, encontramos o gozo circunscrito pelo falo, o que o torna finito e localizável. Do lado feminino, ainda que seu gozo também se articule ao falo, uma parte dele é suplementar, caracterizando o gozo feminino como não localizável e, neste sentido, infinito. A tábua da sexuação foi o artifício lacaniano para escrever a relação de cada sexo com seu gozo.

\footnotetext{
6 Existem algumas formas de periodização do ensino de Lacan. Neste artigo, nos orientamos a partir da divisão em primeira e segunda clínicas. Em resumo, a primeira clínica de Lacan é uma clínica estrutural, onde há uma distinção radical entre neurose, psicose e perversão indicada pela relação do sujeito com o significante do Nome-do-Pai, ou seja, com o simbólico. A segunda clínica, a clínica borromeana, é uma clínica que já não se orienta pelo simbólico, ela articula, sem primazia, os três registros - imaginário, real e simbólico - em um nó singular capaz de sustentar a realidade psíquica para cada sujeito. Para os interessados nesta discussão, sugerimos o artigo de Mattos (2009) A dialética entre a primeira e a segunda clínicas de Lacan, disponível em www.institutodepsicanálise-mg.com.br/psicanalise/almanaque/almanaque5.htm.
} 


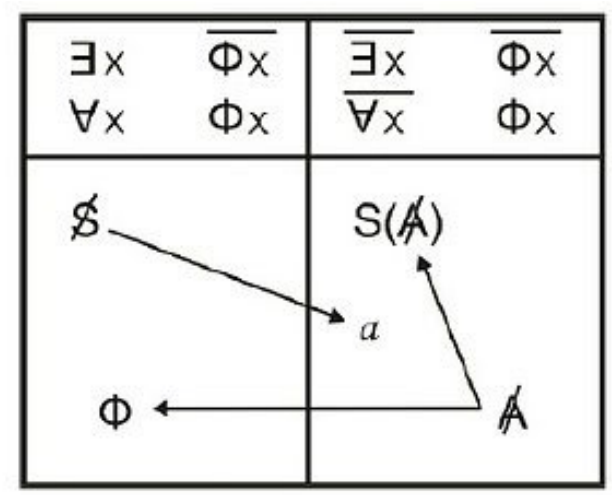

Figura: Recuperado de Lacan (1972-1973/1985, p. 105)

Lacan (1972/1985) propõe um quadro de dois lados, conforme colocado acima a título de ilustração, já que não o exploraremos em todas as suas consequências. Nele, "quem quer que seja falante se inscreve de um lado ou de outro" (p. 107). Ele coloca o pai como primeiro quantificador. A primeira fórmula, do lado esquerdo do quadro, o lado homem, estabelece que uma vez que "não há universal que não deva ser contido por uma existência que o negue" (p. 450), e tal função encontrará seu limite na existência de um "x" que não é castrado. Exceção que remete ao pai da horda primitiva freudiana em Totem e Tabu.

O segundo quantificador, ainda do lado do homem, coloca que, para todo $\mathrm{x}, \mathrm{f}(\mathrm{x})$ é satisfeito, o que "quer dizer que todo sujeito como tal (...) inscreve-se na função fálica - $f(x)$ - para obviar a relação sexual" (Lacan, 1974/2003, p. 458). Portanto, é a exceção do pai, como aquele que não é castrado, que funda o conjunto dos homens limitados em seu gozo. A ordem masculina, como colocou Alvarenga (2015), é uma ordem patriarcal, caracterizada pela concentração do poder e do controle em uma figura de exceção, como o pai da horda de 'Totem e Tabu'. Veremos, na próxima nota, como na contemporaneidade essa ordem está afetada, e como incide nas relações entre os sexos.

A castração, colocada para todos os homens, resulta em uma abertura ao gozo sexual, ao gozo fálico (André, 1998). A função fálica instaura assim, uma proibição de um gozo sem limites, reservado ao pai da horda, para permitir um gozo parcial, o gozo sexual. Essse gozo fálico está ligado à incidência do significante, portanto, pode ser abordado pela fala. Claro está que, quando dizemos gozo fálico, sexual, não estamos limitando esse gozo ao gozo simplesmente carnal. Para Teixeira (2014, p.94), "trata-se do gozo mais comum, gozo do sexo, do trabalho, do sintoma, aquele que o sujeito sempre encontra".

As mulheres, por sua vez, ocuparão o outro lado do quadro. Inscrito nesse lugar, a universalidade do lado homem é perdida, só restando ao ser falante ser não-todo, bem dito, não-todo submetido à função fálica, mesmo não prescindindo dela. Assim, não há mulher que não esteja submetida à castração. Logo, aqui não falamos de uma exceção que possa fundar, de forma lógica, um todo. Isto faz a mulher não-toda, submetida à lei simbólica. Do lado feminino, no entanto, se situa a inconsistência que designa uma estrutura lógica positiva, o espaço não-todo: conjunto aberto justamente pela impossibilidade de fechar o conjunto das mulheres e, por isto, as mulheres só podem ser tomadas uma a uma (Riguini \& Ferrari, 2013).

Colocada desde sempre sob a primazia do falo, à mulher falta um significante que se inscreva no inconsciente e que possa nomear a mulher. Enquanto o homem inscreve-se todo na função fálica, a fim de evitar o confronto da não relação ao supri-la pelo sentido (Lacan, 1972), na mulher, como resultado, encontramos um gozo que ultrapassa o gozo delimitado e enquadrado pelo falo, uma vez que o complexo de castração, nelas, não toca o real do corpo para ordenar o gozo em torno do falo. Assim sendo, a lógica feminina não estará fundada na castração e o gozo retorna ao corpo sem a localização fálica, ou seja, ele é vivido no real do corpo.

No lado direito da tábua é onde, portanto, encontramos a inscrição da parte mulher entre os seres falantes, o Outro sexo. Este Outro, na linguagem lacaniana, "só pode ser, portanto, o Outro sexo" (Lacan, 1972, p. 45). Bem entendido, esse não é o Outro da fala característico das primeiras elaborações lacanianas, pois seria uma forma de dizer o gozo fálico. Esse lugar, não todo fálico, é o lugar da alteridade, situado na dimensão do Outro. É o lugar do héteros, do que escapa à lei da castração.

O gozo do Outro é produzido como mais além do gozo sexual. André (1998, p.223) acrescenta que é a linguagem que nos faz supor um aquém e um além dela mesma. O enigma que uma mulher encarna para um homem está ligado, em grande parte, à suposição que ele faz de um gozo outro que não seja o seu, "justamente porque estamos todos insatisfeitos com o gozo fálico". A mulher se coloca como Outra. A Outra que não o que pode ser nomeado pela cadeia significante organizada no simbólico pela lei do falo e da castração. Para André (1998, p.233), é isto que coloca A Mulher no plano do Outro radical, "do Outro real sexual do qual o inconsciente nada tem a dizer a não ser pela falta".

Tal divisão implica que, de um lado, no lado homem, como colocamos acima, encontramos o gozo fálico, que é causado pelo significante, se inscreve na linguagem, pode ser dito e simbolizado. Mas, do outro lado, encontramos uma forma de 
gozo suplementar, o gozo do Outro, caracterizado pela infinitude, pelo impossível. Isto não quer dizer que as mulheres não têm acesso ao gozo fálico. Quando dizemos que elas inscrevem-se como nãotodas na função fálica, acrescentamos que elas têm acesso a esse Outro gozo. Teixeira (2014) esclarece que a característica desse gozo é a impossibilidade de dizê-lo. O gozo experimentado pelos místicos é o exemplo princeps desse Outro gozo, mas não o mais comum. A aproximação do gozo do Outro ao gozo dos místicos destaca a abolição do sujeito nesse gozo. É o campo da fragmentação.

A questão da diferença sexual inclui-se na dificuldade de pensar a diferença. Poderia ser natural pensar que a ausência de um traço, de um lado, seria a resposta à presença de um traço, do outro lado, e valeria como traço qualificando "Mulher" em oposição a "Homem". Mas a facilidade desaparece quando buscamos estabelecer o próprio que qualifica "Homem" e o próprio que qualifica "Mulher", sem articulá-los. A ausência de traço fálico não tem nenhum valor complementar em relação à sua presença, abrindo, desse único fato, um outro espaço, passível de outras regras. O Outro sexo é justamente o que resiste à identificação, não se pode identificá-lo. O aforismo "Não há relação sexual" pode ser lido desse modo. Pode-se falar do homem como universal, identificando-o ao falo, mas há do outro lado uma ausência, uma alteridade que não é identificável a nenhum significante: "A mulher não existe". Não há um "dois" que entra em relação com um "um".

Foi através dessas elaborações que Lacan pôde dizer da impossibilidade da relação sexual e da inexistência da Mulher. Atravessado pelo gozo fálico, para o homem, a relação com a parceira mulher se reduz à fantasia. Ele só poderá tomá-la parcialmente, nunca tendo acesso ao corpo feminino em sua alteridade absoluta. É impossível a relação sexual, a proporção entre os sexos, dada a heterogeneidade irredutível dos gozos, que acarreta o malogro fundamental do ato sexual.

"Se os homens e as mulheres se deitam juntos é porque, com efeito, eles querem "ainda" se unir ao Outro real, mesmo que se suponha que eles saibam que este está fora do alcance. Pois o horizonte do gozo é de gozar do Outro, do corpo do Outro como tal. O gozo dito sexual faz obstáculo a isto, é defesa contra o gozo do Outro ou do corpo, na medida em que o sexual nos vem da linguagem e dela recebe sua determinação fálica" (André, 1998, p. 238-9).

Algumas consequências, no que tange ao nosso tema, já podem aqui ser tocadas. A depreciação da feminilidade, para Teixeira (2014), está contida na recusa desta Outra dimensão, tomada como perturbadora pelos homens, já que a lógica fálica, como princípio de ordenação, é aqui colocada em questão. Podemos considerar que há, também, uma raiva impotente do homem frente à impossibilidade sexual, como pontuou André (1998). Veremos como essas elaborações incidem nas manifestações de violência contra a mulher em nosso tempo.

\section{Quinta e Última Nota: Horror ao Feminino - soluções da catástrofe à arte.}

Destacamos, neste percurso, o insuportável que uma mulher pode representar para um homem e, muitas vezes, para muitas mulheres. É a ameaça de fragmentação, de dissolução do eu em um gozo sem limites, o que coloca o horror às mulheres ao vislumbrar um gozo que não pode ser escrito e que culmina na ausência de relação sexual. Neste ponto do nosso trabalho, comentaremos algumas soluções encontradas pelos seres falantes, homens ou mulheres, para lidarem com o que há de insuportável no gozo feminino, que se apresenta através do corpo da mulher. Dentre essas soluções, encontramos algumas catastróficas, radicais, que nos apontam para a abolição do sujeito. Dentre elas, o feminicídio. Passamos por outras soluções mais paradigmáticas, como a maternidade ou o amor, e ainda algumas muito singulares, como a de Hans Bellmer, que discutiremos abaixo. A solução de Bellmer, ainda que singular, nos mostra também o rastro de fragmentação colocado pelo gozo feminino. Longe de querermos situar todas as soluções possíveis dos seres falantes frente a esse gozo, pois seria impossível, buscaremos exemplificar algumas a fim de elucidar como, dentro do campo da psicanálise, entendemos as questões que tocam determinados tratamentos do corpo feminino.

Vale lembrar que Freud (1923), em 'A organização genital infantil', diz que, para os meninos, o horror das mulheres deriva, como vimos, da percepção de que as mesmas não têm pênis. A disposição ao homossexualismo masculino também tem, para Freud, sua raiz nessa percepção. A homossexualidade, em alguns casos, pode ser entendida, nas palavras de Freud, como forma de evitação do encontro com a castração.

Para as meninas, Freud (1933) percebe uma dificuldade de aceder à feminilidade, já que depende, mais uma vez, de uma aceitação da castração. Para ele, a feminilidade verdadeira estaria na maternidade, mas a menina pode ainda encontrar dois outros caminhos: a inibição sexual, ou a histeria, e o complexo de masculinidade, ou a identificação ao masculino. Vimos que a maternidade, muitas vezes, vem como resposta ao enigma da feminilidade e, mais exatamente, como forma de localizar algo do gozo feminino. A identificação ao masculino, em outros termos, a escolha por se manter no campo do gozo fálico, também pode ser uma saída feminina frente ao horror do gozo feminino. No entanto, quando Lacan propõe, como visto, as tábuas da sexuação, aponta também que esse gozo pode encontrar uma forma de ser localizado para a assunção da feminilidade, na 
medida em que uma mulher encontre uma maneira de localizar-se como Outra para si mesma (Alvarenga, 2015). Assim sendo, sem tentar circunscrever um ser para si mesma, buscando um todo fálico, mas de uma forma que seja possível a cada uma considerar a sua posição de sujeito em relação ao outro e também a alteridade radical que cada mulher pode ser para si mesma.

E quanto aos homens, como é possível encarar o gozo feminino? Sabemos o quanto esse encontro pode se tornar trágico e devastador. Durante uma festa de Réveillon em 2017, um homem de 46 anos ganhou os jornais quando matou doze pessoas a tiros em Campinas-SP. Dentre as vítimas, nove eram mulheres, sendo uma delas sua exesposa. Nesse ato, matou também seu filho de oito anos e se suicidou depois. O assassino deixou uma carta em que fica claro tratar-se de um feminicídio. Ele fala, repetidas vezes, que as mulheres eram "vadias" e que pretendia matar o máximo de vadias da mesma família - família da ex-companheira - de uma vez. Ele diz também ter raiva das vadias que se reproduzem e se beneficiam da lei "Vadia da Penha", entre outros disparates.

Claro está que não pretendemos aqui analisar as questões desse sujeito, ou mesmo diagnosticá-lo, mas sabemos que não é raro esse tipo de crime. Há, em um primeiro momento, um ataque ao outro que encarna o feminino, em que o sujeito localiza um gozo que não reconhece como seu. Depois vem, por vezes, o suicídio, outras vezes a auto-mutilação, que nos mostram que esses homens matam em si o que os perturbava, mas que não podia ser reconhecido como próprio (Alvarenga, 2015). Tantos são os casos com uma estrutura parecida na história, na mídia, ou na sua vizinhança. São histórias de amores degradados, em que o insuportável da alteridade que carrega o feminino se traduz, como pontua De Francisco (2014), em violência e destruição. A mulher ter algo de inapreensível, de inominável, de incompreensível, desperta no homem um sentimento de impotência tão insuportável, muitas vezes, que só encontra desfecho no ato violento. De Francisco (2014, p.90) pondera, no entanto, que essa impotência que o homem pode sentir nem sempre culminará em violência, "o que quer dizer que nestes casos concorrem determinações edípicas patogênicas". Em alguns casos, podemos mesmo observar que alguns homens exercem violência contra uma determinada parceira, mas, com outra, não.

Podemos pensar, com Lacan, que há um tipo de amor, não degradado, capaz de lidar com os obstáculos da não relação sexual, ou seja, da não proporção entre os gozos. No Seminário 20, Lacan (1972/1985) vai reconsiderar as questões do amor, e até debochar dele. Sua tese é de que o amor vem como suplência à relação sexual que não existe. Mas não se trata de qualquer tipo de amor. Ele nos apresenta um neologismo para falar desse tipo de amor: amuro. Este é um laço que já não se refere ao amor em sua relação com a falta, amor que busca construir uma relação de completude, que quer fazer Um, e que se estabelece sob uma demanda infinita. Para Lacan (1972/1985, p.12), o amor não é capaz de responder sobre o gozo do corpo do Outro e, assim, não cessa de demandar o amor. Ele diz que "quando se olha para lá mais de perto, veem-se as devastações" e acrescenta que, de onde parte, o que é capaz de responder pelo gozo no corpo do Outro não é o amor, mas amuro.

Para Lacan (1972/1985, p. 14), "o amor é impotente, ainda que seja recíproco, porque ele ignora que é apenas desejo de ser Um, o que nos conduz ao impossível de estabelecer a relação dos (...) dois sexos". Nesse seminário, quando fala em amuro, a relação de amor e gozo não é mais de oposição, mas de disjunção. $\mathrm{O}$ amor assim entendido faz um laço, ou um semblante de laço, que, ainda que não faça Um, possa conectar os dois sexos (Teixeira, 2014). Assim, é um tratamento da não relação sexual, do encontro com o gozo do Outro. Neste lugar, o amor não apenas suporta, mas só existe a partir desse real que a mulher encarna.

Uma solução mais singular foi alcançada por Hans Bellmer (1902-1975). Ele foi um artista plástico nascido na Alemanha e, posteriormente, radicado na França. Os desenhos, pinturas, fotografias e esculturas criados por Hans Bellmer têm algo de obscuro, de subterrâneo. Nesse sentido, não nos parecem algo que possa ser feito para se tornar parte do laço social, ter uma função sublimatória, civilizatória, apaziguadora. Seus trabalhos antes desagregam, fragmentam, e mostram o avesso.

Bellmer começa sua vida como artista quando decide construir $A$ Boneca. Esse trabalho de Bellmer choca com imagens de um corpo feminino agredido, amarrado, reduzido à carne, ao informe. A Boneca foi um projeto que começou com uma escultura de uma mulher articulada, estranha, desmembrada, que, posteriormente, era fotografada em várias posições e situações. Foram construídas duas bonecas na década de 1930. Elas mediam em torno de 1,60m e foram feitas de madeira, metal, gesso e juntas esféricas. Na primeira série de fotografias, publicada em 1934 como A Boneca, observamos um trabalho contínuo de deformação do corpo feminino. Na segunda série, publicada em 1949 como Variações sobre uma menor articulada, Bellmer busca a comunicação de experiências, do terror e da fantasia. Além da segunda Boneca ser mais deliberadamente desmembrada, as montagens de cenas sádicas também foram mais enfatizadas dessa vez.

No trabalho com as Bonecas, mesmo em seus desenhos, Bellmer estabelece a anatomia de seu desejo e termina por demonstrar o "sepulcral de seu erotismo" enquanto sujeito masculino: a própria fragmentação, a dissolução (Foster, 2008, p. 189). Ao mesmo tempo, continua Foster, este é seu maior desejo: escapar do contorno de si mesmo. Neste ponto, há uma conversão de desejo e identificação de Bellmer com as bonecas. As bonecas, objetos eróticos do artista mas também objetos de identificação, revelam a fragmentação de um gozo experimentado no corpo, não circunscrito falicamente, que Bellmer busca localizar fora.

Em 1957, o artista publica um livro começado em 1936, ou seja, na mesma época em que trabalha com as Bonecas, intitulado "Petite Anatomie de l'inconscient physique ou l'anatomie de l'image". Neste texto, Bellmer traça, de maneira 
fina e rigorosa - como era seu estilo -, suas intenções picturais, além de fazer uma análise do processo mental que, para ele, determina formas e imagens. Ele descreve uma concepção própria do que é um corpo ao falar de um corpo em desacordo com a imagem perceptiva, um corpo desenhado. Esse corpo é desenhado, segundo Bellmer, por traços de memória, e costurado em uma imagem psíquica. Ao se apropriar deste processo, ao desenhar a realidade da vida psíquica, ele desnuda um corpo que goza. Curiosamente, esse corpo é feminino, quer seja na representação das bonecas dilaceradas, quer seja nos desenhos de mulheres deformadas pela multiplicação de membros e desarmonia geométrica.

Bellmer acrescenta que o homem comum quer dar a medida para a mulher, de acordo com um "bom senso" estético. "O homem superpõe à imagem da mulher, suas certezas elementares, os hábitos geométricos e algébricos de seu pensamento" (Bellmer, 1936/2002, p.28). Ele, por sua vez, quer ver dentro delas, investigar suas possibilidades, destruir a boa forma e, acrescentamos, buscar um gozo para além dos limites fálicos.

Tal projeto estava, em parte, de acordo com os preceitos surrealistas, uma vez que esse movimento visava oferecer aos objetos novas e infinitas formas de uso que liberariam os mesmos de sua função - industrial e utilitarista. Mas Bellmer mostrava um erotismo muito próprio, permanecendo marginalizado nesse grupo. O grupo surrealista guiado por André Breton insistia na resistência do objeto ausente e se implicava na busca de um objeto perdido; já Bellmer colocava em cena o questionamento sobre um objeto encontrado, a mulher vítima. Segundo o próprio Bellmer, nele era possível ver um "homem com antenas que captam a mulher vítima" (Bellmer citado por Foster, 2008, p. 168).

Em outro trabalho (Riguini \& Marcos, 2017) consideramos a hipótese de que a invenção da Boneca funciona como uma solução criada pelo artista para lidar com este gozo ilimitado e mortífero: o gozo da fragmentação e da dissolução do eu. Nesse sentido, o horror ao feminino é um horror à própria fragmentação imposta pelo Outro gozo. Em nossa pesquisa reconhecemos ainda que a proposta de Bellmer é desarticular o corpo-imagem, feito à medida do desejo, para encontrar 0 corpo-objeto destituído da imagem que é erigida sobre a falta fálica; o que fica descoberto é um gozo sem limites, um corpo sem imagem, uma forma sem ideal.

Bellmer nos mostra um corpo cujos limites entre ele, o outro ou a realidade se tornam inócuos. Ao que parece, para ele, em relação ao corpo, havia uma necessidade de traduzir a realidade corporal, de talhar um corpo fora do corpo, necessidade que passava pelo trabalho artístico. Aqui, nos interessa marcar um ponto: para Bellmer, a imagem é um corte na carne. Ele fala, em sua Petite Anatomie (1936/2002), de um artesão criminoso, aquele que "pratica a paixão humana mais sublime e bela", aquela que é capaz de suprimir a parede entre uma mulher e sua imagem. Assim, ele busca um corpo que não é o corpo-imagem, mas carne talhada pela memória e pelo desejo - arriscamos a dizer, em outras palavras, pelo gozo.

Articulado ao tema do feminicídio, a obra de Hans Bellmer nos mostra a presença deste gozo Outro, não articulado pela imagem, pelo eu e pelo todo. Mas o artista também mostra, para além disso, que é possível lidar com o horror que esse gozo provoca de várias maneiras. Se, para alguns, a solução passa por aniquilar o sujeito feminino; para outros encontraremos novas saídas. $\mathrm{O}$ artista inventa uma solução muito singular, capaz de localizar o Outro gozo em um corpo fora de seu corpo, mantendo-se afastado da fragmentação e da dissolução que produziria em seu corpo próprio.

Com as soluções comentadas acima, voltamos a lembrar a diferença da abordagem da psicanálise sobre o problema do feminicídio. Longe de acreditamos em uma solução pela igualdade de gêneros - ainda que sustentamos a necessidade de políticas e direitos para as mulheres - , buscamos saídas, caso a caso, para homens e mulheres, para o encontro com o feminino. A psicanálise não se baseia na diferença anatômica, mas coloca em jogo e lida com o gozo Outro, não-todo, e suas consequências.

Sem tentar finalizar esta discussão que, por sua própria matéria, é ilimitada, podemos concluir, com as notas desenvolvidas e com as soluções vistas, que o não-todo não pode ser saturado por nenhum todo. Para a psicanálise, não se enfrenta este tipo de violência, o feminicídio, com a máscara do masculino, a máscara do falo, nem com uma vitimização da mulher, mas no encontro e no tratamento da alteridade, no encontro de cada mulher com aquilo que a faz estrangeira de si mesma.

\section{Referências}

Alvarenga, E. (2015). As mulheres e a violência de nossos tempos. Opção Lacaniana online.17, 1-12. Link

André, S. (1998). O que quer uma mulher? Rio de Janeiro: Jorge Zahar.

Bassols, M. (2012). La violencia contra las mujeres: Cuestiones Preliminares a su tratamiento desde el psicoanálisis. Link

Bellmer, H. (2002). Petite Anatomie de l'image.Paris: Editions Allia. (Originalmente publicado em 1936)

Chemama, R. (1995). Diccionario de Psicoanalisis. Buenos Aires: Amorrotu Editores. 
Dafunchio, N. S. (2008). Confines de las psicoses. Buenos Aires: Del Bucle.

De Francisco, M. (2014). La violencia contra la mujer. In P. Sawicke \& B. Stillo. Relaciones violentas: Entre el amor y la tragedia (pp. 78-93). Olivo: Grama Ediciones.

Delumeau, J. (1990). Os agentes de Satã III: A mulher. In Delumeau J. História do medo no ocidente (pp. 234-356). São Paulo: Companhia das Letras.

Freud, S. (1996a). O Tabu da virgindade. In F. Sigmund. Obras psicológicas completas de S. Freud: Edição standard brasileira (Vol. 11, pp. 197-217). Rio de Janeiro: Imago. (Originalmente publicado em 1917)

Freud, S. (1996b). A organização genital infantil: Uma interpolação na teoria da sexualidade. In F. Sigmund. Obras psicológicas completas de S. Freud: Edição standard brasileira (Vol. 19, pp. 155-164). Rio de Janeiro: Imago. (Originalmente publicado em 1923)

Freud, S. (1996c). Algumas consequências psíquicas da distinção anatômica dos sexos. In F. Sigmund. Obras psicológicas completas de S. Freud: Edição standard brasileira (Vol. 19, pp. 155-164). Rio de Janeiro: Imago. (Originalmente publicado em 1923)

Galo, H., Jaramillo, A. M., Marroquin, R. D. L., \& Ramirez, M. E. (2010). Feminidades. Medellin: Editorial Universidad de Antioquia.

Gana, A. L. (2013). Mujeres Maltratadas. Letras Lacanianas, (6), 7-18. Link

Instituto Patrícia Galvão. (2016). Dossiê sobre feminicídio. Link

Lacan, J. (1985). O Seminário: Livro 20: Mais ainda. Rio de Janeiro: Jorge Zahar. (Originalmente publicado em 1972-73).

Lacan, J. (1998a). Diretrizes para um Congresso sobre a sexualidade feminina. In Escritos (pp. 734-748). Rio de Janeiro: Jorge Zahar Editora. (Originalmente publicado em 1960)

Lacan, J. (1998b). A significação do falo. In Escritos (pp. 692-704). Rio de Janeiro: Jorge Zahar Editora. (Originalmente publicado em 1958)

Lacan, J. (2003). Televisão. In Outros Escritos (pp. 508-543). Rio de Janeiro: Jorge Zahar. (Originalmente publicado em 1974)

Marotta, M. (2014). Violência, sintoma social de la época? In P. Sawicke \& B. Stillo. Relaciones violentas: Entre el amor y la tragedia (pp. 13-18). Olivo: Grama Ediciones.

Ons, S. (2012). Comunismo sexual. Buenos Aires: Editora Paidós.

Riguini, R. D., \& Ferrari, I. F. (2013). A comédia dos sexos nas parcerias amorosas. Analytica: Revista de Psicanálise da UFSJ, 2(2). 94-116

Riguini, R. D., \& Marcos, C. M. (2017). Hans Bellmer e a invenção da boneca: o empuxo-à-mulher e a construção de um corpo fora. Revista de Psicanálise da SPPA, 24(1). 135-154

Teixeira, M. R. (2014). Os gozos: Sobre duas dicotomias presentes no Seminário 20: Mais ainda. In Teixeira, M. R. Vestígios do gozo (pp. 88-99). Salvador: Ágalma.

Ubieto, J. R. (2008). Posiciones subjetivas em lós fenômenos de maltrato. Virtualia, 18, 1-4. Link 


\section{Endereço para correspondência}

Renata Damiano Riguini

Email: rriguini@gmail.com

Cristina Moreira Marcos

Email: cristinammarcos@gmail.com

Recebido em: 09/02/2017

Revisado em: 22/01/2018

Aceito em: 10/03/2018 